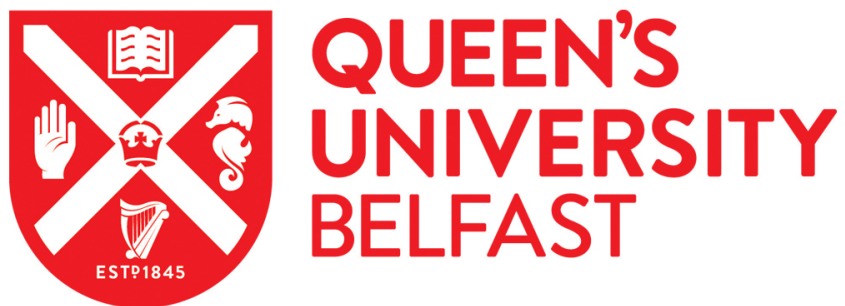

\section{Illness perceptions among carer-survivor dyads are related to psychological distress among Oesophageal cancer survivors}

\author{
Dempster, M., McCorry, N. K., Brennan, E., Donnelly, M., Murray, L. J., \& Johnston, B. T. (2011). Illness \\ perceptions among carer-survivor dyads are related to psychological distress among Oesophageal cancer \\ survivors. Journal of Psychosomatic Research, 70(5), 432-439. https://doi.org/10.1016/j.jpsychores.2010.07.007
}

Published in:

Journal of Psychosomatic Research

Document Version:

Peer reviewed version

Queen's University Belfast - Research Portal:

Link to publication record in Queen's University Belfast Research Portal

Publisher rights

Copyright 2010 Elsevier.

This manuscript is distributed under a Creative Commons Attribution-NonCommercial-NoDerivs License

(https://creativecommons.org/licenses/by-nc-nd/4.0/), which permits distribution and reproduction for non-commercial purposes, provided the author and source are cited.

\section{General rights}

Copyright for the publications made accessible via the Queen's University Belfast Research Portal is retained by the author(s) and / or other copyright owners and it is a condition of accessing these publications that users recognise and abide by the legal requirements associated with these rights.

Take down policy

The Research Portal is Queen's institutional repository that provides access to Queen's research output. Every effort has been made to ensure that content in the Research Portal does not infringe any person's rights, or applicable UK laws. If you discover content in the Research Portal that you believe breaches copyright or violates any law, please contact openaccess@qub.ac.uk. 
Illness Perceptions among Carer-Survivor Dyads are Related to Psychological Distress among Oesophageal Cancer Survivors

Martin Dempster PhD, Noleen K. McCorry PhD, Emma Brennan BSc School of Psychology, Queen's University Belfast, N. Ireland Michael Donnelly PhD, Liam J. Murray MD

School of Medicine \& Dentistry, Queen's University Belfast, N. Ireland Brian T. Johnston MD

Royal Group of Hospitals, Belfast Health \& Social Care Trust, N. Ireland

Running head: ILLNESS PERCEPTIONS AMONG CARER-SURVIVOR DYADS

Corresponding author:

Martin Dempster

School of Psychology, Queen's University Belfast, University Road, Belfast, Northern Ireland, BT7 1NN

Tel: +442890975547

Fax: +442890664144

Email: $\underline{\text { m.dempster@qub.ac.uk }}$ 


\begin{abstract}
Objective

To examine the extent to which the illness perceptions of oesophageal cancer survivors and the illness perceptions of their carers explain the survivors' levels of psychological distress (in terms of anxiety and depression symptoms) relative to demographic and biomedical variables and patients' coping strategies.

Method
\end{abstract}

Everyone registered with the Oesophageal Patients' Association in the UK was mailed a questionnaire booklet containing questions about medical and demographic variables, the Illness Perception Questionnaire-Revised, the Cancer Coping Questionnaire and the Hospital Anxiety and Depression Scale. Patients were asked to pass a modified version of the Illness Perception Questionnaire-Revised to someone they identified as a carer. Complete responses were received from 317 dyads.

Results

Regression models indicated that the variables measured could explain $56 \%$ of the variance in anxiety and 54\% of the variance in depression. Patients' illness perceptions explained the majority of this variance. Positive focus coping strategies were also found to be important in explaining psychological well-being. Some of the carers' illness perceptions made a significant contribution to the explanation of the patients' levels of psychological distress and, in some instances, carer perceptions were found to moderate the relationship between patients' perceptions and psychological distress.

Conclusion

The findings suggest that cognition-based interventions could potentially be most effective in minimizing emotional distress among survivors of oesophageal cancer. This study also shows that these interventions could usefully be delivered at the level of the patient-carer dyad. 
Keywords:

Cancer; oesophagus; carers; depression; anxiety 


\section{Introduction}

In order to develop effective interventions to address psychological distress among people diagnosed with cancer, it is important that we understand the types of cognitions that are associated with higher levels of distress among this population. Research (particularly focused on women with breast cancer) indicates that anxiety and depression is associated with the type of coping strategies adopted and the person's perceptions of their cancer (1-4). Consequently, Leventhal's Self-Regulatory Model (5) may be a useful approach to clarifying the interrelationships among these cognitive and emotional constructs.

Leventhal's Self-Regulatory Model (SRM) suggests that when an individual is confronted with an illness or condition, they will attempt to assign meaning to this illness by accessing their perceptions about the illness. These illness perceptions will be influenced by the individual's emotional state and their emotional state will be influenced by their perceptions of the illness. The SRM proposes that, in an effort to restore normal functioning, individuals will develop coping strategies (based on their illness perceptions and emotional state), which will then be evaluated in terms of their success in restoring equilibrium. The result of this evaluation may be a change in coping strategy and/or a change in perceptions about the illness. In summary, the model suggests that a person's perceptions about an illness and their coping strategies can have an impact on their psychological well-being.

Research using quantitative methodologies has tended to focus on the illness perceptions component of the model and there is a growing body of research demonstrating strong relationships between illness perceptions and (physical and psychological) health outcomes (6). Illness perceptions, as assessed by the Illness Perception QuestionnaireRevised, (7) are mental representations of illness by the individual within various domains: time line (acute/chronic), time line (cyclical), personal control, treatment control, consequences, cause and illness coherence. 
Illness perceptions have been shown to explain a significant proportion of the variance in psychological distress in head and neck cancer $(8,9)$ and in breast cancer $(10)$, even after controlling for disease-related variables. However, the nature of the relationships between illness perceptions and psychological distress differ between the different types of cancer. This clearly suggests that the factors which may impact on psychological health are specific to the type of cancer of interest. However, no published research has examined the relationship between illness perceptions and psychological health among survivors of oesophageal cancer. The present study will address this gap.

Furthermore, previous research suggests that the levels of psychological distress experienced by people with chronic illness can also be affected by the illness perceptions of family carers (11-13). This previous research indicates that in some situations, incongruence in couples' perceptions is detrimental to psychological health. For example, the mood of women with breast cancer is affected detrimentally when their assessment of their adjustment to breast cancer is incongruent with their husband's assessment (13) and the incongruence of perceptions of controllability over infertility between a women and her partner has been shown to be related to distress (11). Yet, in other situations, incongruence appears to be a positive outcome. For example, people with eating disorder who did not agree with the illness perceptions expressed by their relatives were less distressed than those who agreed with their relative's perceptions of eating disorder (12). Again, therefore, the effect of the illness perceptions held by the carer on the distress experienced by the patient may be conditionspecific.

In summary, previous research indicates that illness perceptions are useful in explaining the levels of psychological distress experienced by people with chronic illness and that the illness perceptions held by their carers might also impact on these levels of distress. However, given the condition-specific nature of these relationships, it is important to 
investigate the nature and extent of these relationships within the oesophageal cancer population. Therefore, the specific research questions which will be addressed are:

1. To what extent do the illness perceptions of oesophageal cancer survivors and the illness perceptions of their carers explain psychological distress (in terms of anxiety and depression symptoms), relative to demographic and biomedical variables, among these survivors of oesophageal cancer?

2. To what extent do the survivors' coping strategies influence or mediate these relationship between illness perceptions and psychological distress?

\section{Method}

Participants were recruited via the Oesophageal Patients' Association (OPA) UK database. The OPA is a support group formed to help patients and their families cope with the difficulties arising from the treatment associated with oesophageal cancer. Cancer survivors on the database were mailed a questionnaire booklet containing items relating to demographic information (sex, age and whether there was someone in their life who they would label a “carer”), medical history (time since diagnosis, number of comorbidities, number of symptoms experienced during the previous month that were considered to be related to oesophageal cancer) and the following questionnaires:

The Hospital Anxiety and Depression Scale (HADS) (14). This is a 14 item scale which is divided into two dimensions - anxiety ( 7 items) and depression (7 items). Respondents choose one from four responses to each item. Their responses are then summed within dimensions and a total score for each dimension is obtained, with higher scores representing higher levels of anxiety and depression. Scores for the anxiety dimension and the depression dimension can be categorised as follows: 0-7: normal, 8-10: mild, 11-14: moderate, 15-21: severe. The HADS has been validated among a population of people with 
cancer (15) and is the most frequently used screening tool for psychological distress in cancer care (16).

The Cancer Coping Questionnaire (CCQ) (17). This is a 21 item questionnaire which assesses 5 dimensions: reflection/relaxation coping, positive focus, diversion, planning and use of interpersonal support. Higher scores on each scale indicate that this coping strategy is used more often. Psychometric properties are sound (17).

Illness Perception Questionnaire - Revised (IPQ-R) (7). This questionnaire was used to assess the following illness cognitions: time line acute/chronic, time line cyclical, personal control, treatment control, consequences, cause and illness coherence. Higher scores on the personal control and treatment control scales indicate that the person has a stronger belief in the effectiveness of their ability or the treatment to control the symptoms of oesophageal cancer; higher scores on the consequences scale suggests that the person perceives more severe consequences of oesophageal cancer; higher scores on the illness coherence scale indicates that the person has a clearer understanding of the condition; higher scores on the timeline acute/chronic and timeline cyclical scales indicate a stronger belief that the condition is chronic (rather than acute) and goes through cycles of getting better and worse rather than remaining stable. The 18 items which measure the perceptions of the causes of oesophageal cancer were factor analysed (in line with the questionnaire authors' suggestion) and were found to load on 3 factors, which were labelled emotional causes (e.g. stress or worry), behavioural causes (e.g. smoking or alcohol) and externalised causes (e.g. hereditary or a virus). Higher scores on the cause scales indicate a stronger belief that this was a cause of the oesophageal cancer. The IPQ-R has sound psychometric properties, with evidence for construct, discriminant and predictive validity and for internal and test-retest reliability (7).

In addition, survivors were asked to pass a questionnaire to someone who they identified as carer. Carers were asked to provide some demographic information (sex, age 
and their relationship to the cancer survivor they cared for) and to complete a modified version of the IPQ-R, following the strategy of Barrowclough and colleagues (18). In this modified version of the IPQ-R, the illness perceptions of personal control, consequences and illness coherence were addressed from 2 perspectives. Firstly, carers were asked about their perceptions of their personal control over oesophageal cancer, the consequences of the condition for their lives and their understanding of the condition. Secondly, carers were asked about their perceptions of the personal control that the survivor could exert over the condition, their perceptions of the effect of the condition on the survivor's life and their perceptions of the survivor's understanding of the condition. For the remaining dimensions of the IPQ-R, the carers were asked for their perceptions about the chronic/acute nature of oesophageal cancer, the cyclical nature of oesophageal cancer, the extent to which treatment can control or cure the condition, and the cause of oesophageal cancer.

\section{Statistical Analysis}

There has been considerable variation in the methods used in previous literature to examine the illness perceptions of dyads and their relationship to psychological distress. Patient and relative scores have been categorized in terms of their similarity or dissimilarity $(12,19)$; relative scores have been subtracted from patient scores to provide an estimate of incongruence (13,20-22); and patient and relative scores have been entered as separate covariates in a regression analysis $(23,24)$. However, for our analyses, we hypothesized that the carer's illness perceptions may moderate the relationship between the survivor's illness perceptions and their level of psychological distress (see 11,25). Therefore, we conducted separate regression analyses for each outcome variable (anxiety and depression), with each survivor and carer illness perception and the interaction term between the survivor and carer entered as covariates (all variables were standardized). Interaction terms that contributed significantly to the regression model after the inclusion of the survivor and carer illness 
perceptions were retained for inclusion in the final regression analyses. In the final regression analyses, hierarchical regression models were developed for each outcome variable.

Covariates in the first block were medical/demographic variables, all of the carer and survivor illness perceptions and any retained interaction terms were added in the second block and survivor coping strategies were added in block 3. In this way, we could detect if the addition of the coping strategies caused a significant change in the regression coefficients of the covariates entered in the first 2 blocks, thereby suggesting that further investigation of the potential mediating effects of coping would be warranted.

For each regression model, a backward elimination procedure was conducted, where the covariate with the lowest absolute standardised regression coefficient was removed and then the regression model recalculated. This iterative procedure was conducted until the adjusted R-squared value did not increase any further, thereby providing the most parsimonious model.

\section{Results}

A total of 1,858 oesophageal cancer survivors were mailed questionnaires and 594 were returned (32\% response rate), with 458 survivors providing complete data on all the questionnaires ( $25 \%$ completion rate). Of the 594 questionnaires returned, 590 completed the HADS. There were only small differences on the HADS scores between the 458 survivors who completed and returned all the questionnaires and the 132 survivors who returned incomplete questionnaires. The mean (SD) anxiety score for completers was 6.25 (4.82) and for non-completers was $6.70(5.00)(t=0.948, p=.343)$; the mean (SD) depression score for completers was $4.85(4.00)$ and for non-completers was $5.72(4.34)(\mathrm{t}=2.170, \mathrm{p}=.030)$.

Almost 12\% (54/458) of the oesophageal cancer survivors indicated that there was no-one who could be considered a carer. There were no significant differences between the survivors who identified a carer $(n=404)$ and the survivors who did not identify a carer 
$(\mathrm{n}=54)$ in terms of anxiety $(\mathrm{t}=0.379, \mathrm{p}=.705)$ or depression $(\mathrm{t}=0.782, \mathrm{p}=.435)$ scores. Of the 404 carers, complete responses on all questionnaire scales were obtained from 317 . The findings reported relate to the 317 survivor-carer dyads only.

Oesophageal cancer survivors were, on average, 64 years old $(\mathrm{SD}=9.64)$, while carers were, on average, 62 years old $(\mathrm{SD}=10.78)$. Approximately $71 \%(225 / 317)$ of the survivors were male and 74\% (233/317) of the carers were female, which is not surprising given that the majority of carers $(301 / 317 ; 95 \%)$ were the spouse or partner of the survivor. The survivors had been diagnosed with oesophageal cancer for a median time of 48 months prior to completing the questionnaire (17\% diagnosed less than 1 year ago; $15 \% 1$ to 2 years; $9 \% 2$ to 3 years; $13 \% 3$ to 4 years; $12 \% 4$ to 5 years; $6 \% 5$ to 6 years; $7 \% 6$ to 7 years; $21 \%$ beyond 7 years and up to 37 years). Based on available statistics about oesophageal cancer in the UK in 2006 (64\% male) and the 1 year (30\%) and 5 year (8\%) survival rates (26), the sample in this study appear to be representative of people with a diagnosis of oesophageal cancer in the UK.

Descriptive statistics are presented in Table 1. Carers reported significantly higher anxiety scores than survivors. Survivors felt that they could control their condition more than carers felt they could control the condition and more than carers felt that the survivors could control the condition. Carers rated the consequences of the condition for the survivor as more severe than the survivors but the carers believed that the condition had a small impact on their lives.

- Table 1 here -

For all 3 hierarchical regression models, the statistical significance of the regression coefficients was not influenced by the addition of blocks and therefore the final and most parsimonious regression model only is presented in each case. 
The regression model specified in Table 2 explained $57 \%$ of the variance in levels of anxiety (adjusted $\left.\mathrm{R}^{2}=54 \% ; \mathrm{F}(17,299)=22.930, \mathrm{p}<.001\right)$. The medical and demographic variables contributed $12 \%$ of the variance explained and the illness cognitions variables contributed an additional 37\%; with the coping variables contributing the remaining $7 \%$.

- $\quad$ Table 2 here -

The regression model specified in Table 3 explained 53\% of the variance in levels of depression (adjusted $\left.\mathrm{R}^{2}=51 \% ; \mathrm{F}(18,298)=18.916, \mathrm{p}<.001\right)$. The medical and demographic variables contributed $12 \%$ of the variance explained and the illness cognitions variables contributed an additional 35\%; with the coping variables contributing the remaining $6 \%$.

- $\quad$ Table 3 here -

A single interaction term is present in both models and makes a statistically significant contribution to each model. With anxiety as the outcome variable, there is an interaction between the survivor's and the carer's perception of consequences for the survivor. A simple slope analysis suggests that survivor anxiety increases as their strength of perception of severe consequences increases and this increase in survivor anxiety is particularly pronounced when the carer also believes more strongly that the oesophageal cancer has severe consequences for the survivor (see Figure 1).

- Figure 1 here -

With depression as the outcome variable, there is an interaction between the survivor's and carer's perception of the survivor's illness coherence. A simple slope analysis suggests that as the survivor's illness coherence decreases, their level of depression increases and the level of depression is highest when the carer believes that the survivor's illness coherence is high. Notably, when the survivor's illness coherence is high, the carer's perception appears to have little effect on the survivor's level of depression (see Figure 2).

- $\quad$ Figure 2 here - 


\section{Discussion}

The research presented here indicates that oesophageal cancer survivors experience levels of symptoms of anxiety and depression similar to that reported for people with other head and neck cancers $(8,27)$ but higher than rates reported for other breast, prostate, bronchial and gastrointestinal cancers $(28,29)$. It is possible that the higher rates of psychological distress can be explained by the consequences of oesophageal and head and neck cancer, which have a potential impact on appearance and social functioning (30). However, no previously published research exists which has examined the factors that help us to explain psychological distress among oesophageal cancer survivors.

In our sample, after controlling for demographic and medical variables, the illness perceptions and coping variables contributed the majority of the explained variance in psychological distress. Specifically, survivors were less likely to report poor psychological health when they: perceived less severe consequences from their condition; perceived more personal control over their condition; were more likely to believe that they understand their condition; and were less likely to believe that their oesophageal cancer was caused by stress or poor emotional health. Additionally, maintaining a positive focus appears to minimize psychological distress, whereas spending more time relaxing and reflecting or engaging in diversionary coping strategies is associated with poor psychological health.

Furthermore, the carer's perception of oesophageal cancer also appears to play an important role in the psychological health of the patient. In our sample, survivors were more likely to report high levels of psychological distress when the carer reported that the condition had severe consequences for the survivor or when the carer believed that the medical staff had little control over the condition. Perhaps these perceptions are indicating a sense of hopelessness on the part of the carer that is in some way being transmitted to the survivor. Indeed, significant interactions were found, indicating that the relationship between 
some survivor perceptions and their psychological health depends on the carer's perceptions, in a more complex manner than an analysis of (dis)similarity in perceptions would have revealed. We believe that this is the first time that the moderating effect of carer's illness perceptions have been shown in an examination of the psychological distress of people with cancer. Previous research examining the effect of relatives' or carers' perceptions on psychological adjustment of patients with other chronic illness indicates mixed results in that in some cases the relative's perceptions are not related to the patient's psychological distress $(20,23)$, whereas in other research there is a relationship $(11,12,19,21,22,25)$. However, even in this latter group of research studies, the specific illness perceptions which correlate significantly with patient distress differ, perhaps as a result of the different chronic illnesses under investigation. This highlights the importance of ensuring that dyadic perceptions are researched within the population of interest, rather than transferring results from previous research conducted in different populations.

In summary, it appears that in order to optimize psychological well-being among survivors of oesophageal cancer, it would be useful to develop interventions which were delivered at the level of the dyad and were focused on illness perceptions and coping. The illness perceptions which need to be targeted are perceptions of: consequences, cause, control and understanding of the condition. Providing clear and coherent information about oesophageal cancer is, therefore, perhaps an important protective factor against psychological distress. In addition, positive focus coping strategies need to be facilitated and reflection and diversionary coping strategies should be discouraged.

The results of this study are consistent with previous research demonstrating that illness perceptions are stronger correlates of adaptive outcomes than coping scores (31-33), thereby suggesting that cognition-based interventions could potentially be most effective in minimizing emotional distress. However, the findings concerning coping strategies are 
limited by the choice of instrument (CCQ) in this study. The psychometric properties of this instrument is sound, but the types of coping strategies included in our analyses are limited to those assessed by the CCQ, which does not cover a range of coping strategies as broad as that addressed by other instruments such as the COPE (34). Nevertheless, the CCQ is more specifically focused on coping with cancer rather than coping in general. Furthermore, the cross-sectional design of this study limits the conclusions that can be drawn about the direction of these relationships. It may be the case that psychological health (in terms of anxiety and depression) influences the development of illness cognitions and so the direction of action could be the opposite of that proposed in the regression models in the present study. An exploratory intervention trial could help to establish the direction of cause and effect but prior to embarking on such a resource-intensive endeavour, further modelling work using data derived from longitudinal research, to examine the relationship between changes in cognitions and changes in psychological well-being would be useful in strengthening the case for moving to an intervention. Some initial longitudinal work among people with head and neck cancer indicates that an intervention based on illness perceptions may be useful for increasing quality of life (8), and some information guiding the design of illness perception based interventions in head and neck cancer have recently been published (35). These interventions draw heavily on the principles of cognitive behavioural therapy and could be adapted to address the specific illness perceptions highlighted in the research presented here. Therefore, we suggest that this approach may be a useful method of addressing psychological ill-health among survivors of oesophageal cancer.

The study findings are also potentially limited because they are based on a minority $(25 \%)$ of the oesophageal cancer survivors who had registered with a patient support group (the Oesophageal Patients' Association). It is possible that patients involved with a support group may differ from other patients, in terms of important psychological constructs and it is 
possible that our response rate resulted in a bias sample in terms of the psychological constructs assessed. However, the sample in the present study had similar scores on an assessment of psychological health when compared with survivors of other head and neck cancers $(8,27)$.

In conclusion, it is important to note that most survivors of oesophageal cancer are in good psychological health and do not require formal interventions. Although, given that the majority of the survivors in our sample were at least 3 years post-diagnosis, perhaps this implication should be limited to longer term survivors of oesophageal cancer. Indeed, a sizeable proportion of oesophageal cancer survivors have clinically significant symptoms of anxiety and/or depression that can largely be explained by their perceptions of oesophageal cancer. These perceptions are modifiable and, therefore, appropriately tailored and targeted interventions could have beneficial effects for the quality of life of survivors of oesophageal cancer. 


\section{Acknowledgements}

This research was supported by a grant from Action Cancer, Northern Ireland and facilitated by David Kirby and staff at the Oesophageal Patients' Association UK

\section{References}

1. Carver CS, Pozo C, Harris SD, Noriega V, Scheier MF, Robinson DS, Ketcham AS, Moffat FL, Clark KC. How coping mediates the effect of optimism on distress: A study of women with early stage breast cancer. J Personality Soc Psychol 1993;65:375-390.

2. Osowiecki D, Compas BE. Psychological adjustment to cancer: Control beliefs and coping in adult cancer patients. Cognitive Therapy Res 1998;22:483-499.

3. Schou I, Ekeberg O, Ruland CM, Sandvik L, Karesen R. Pessimism as a predictor of emotional morbidity one year following breast cancer surgery. Psycho-Oncol 2004;13:309320.

4. Watson M, Greer S, Rowden L, Gorman C, Robertson B, Bliss JM, Tunmore R. Relationships between emotional control, adjustment to cancer and depression and anxiety in breast cancer patients. Psychol Med 1991;21:51-57.

5. Leventhal H, Meyer D, Nerenz D. The common sense representation of illness danger. Med Psychol 1980;2:7-30.

6. Cameron LD, Moss-Morris R. Illness-related cognition and behaviour. In: Kaptein A, Weinman J, eds. Health Psychology. Oxford: BPS Blackwell 2004;84-110. 
7. Moss-Morris R, Weinman J, Petrie KJ, Horne R, Cameron LD, Buick D. The revised Illness Perception Questionnaire (IPQ-R). Psychol Health 2002;17:1-16.

8. Llewellyn CD, McGurk M, Weinman J. Illness and treatment beliefs in head and neck cancer: Is Leventhal's common sense model a useful framework for determining changes in outcome over time? J Psychosom Res 2007;63:17-26.

9. Scharloo M, Baatenburg de Jong R, Langeveld TPM, van Velzen-Verkaik RN, Doorn-op den Aaker MM, Kaptein AA. Quality of life and illness perceptions in patients with recently diagnosed head and neck cancer. Head Neck 2005;27:857-863.

10. Miller K, Purshotham AD, McLatchie E, George D, Murray GD. A 1-year prospective study of individual variation in distress and illness perceptions after treatment for beast cancer. J Psychosom Res 2005;58:335-342.

11. Benyamini Y, Gozlan M, Kokia E. Women's and men's perceptions of infertility and their associations with psychological adjustment: A dyadic approach. Brit J Health Psychol 2009;14:1-16.

12. Quiles Marcos Y, Weinman J, Terol Cantero MC, Belendez Vazquez M. The dissimilarity between patients' and relatives' perception of eating disorders and its relation to patient adjustment. J Health Psychol 2009;14:306-312. 
13. Romero C, Lindsay JE, Dalton WT, Nelson DV, Friedman LC. Husbands' perceptions of wives' adjustment to breast cancer: The impact on wives' mood. Psycho-Oncol 2008;17:237243.

14. Snaith RP, Zigmond AS. The Hospital Anxiety and Depression Scale. Acta Psychiatrica Scand 1983;67:361-370.

15. Smith AB, Selby PJ, Velikova G, Stark D, Wright EP, Gould A, Cull A. Factor analysis of the Hospital Anxiety and Depression Scale from a large cancer population. Psychol Psychotherapy 2002;75:165-176.

16. Reuter K, Härter M. Screening for mental disorders in cancer patients - discriminant validity of HADS and GHQ12 assessed by standardized clinical interview. Int J Methods Psychiatric Res 2001;10:86-96.

17. Moorey S, Frampton M, Greer S. The Cancer Coping Questionnaire: A self-rating scale for measuring the impact of adjuvant psychological therapy on coping behavior. PsychoOncol 2003;12:331-344.

18. Barrowclough C, Lobban F, Hatton C, Quinn J. An investigation of models of illness in carers of schizophrenia patients using the Illness Perception Questionnaire. Brit J Clin Psychol 2001;40:371-385.

19. Figueiras MJ, Weinman J. Do similar patient and spouse perceptions of myocardial infarction predict recovery? Psychol Health 2003;18:201-216. 
20. Law GU. Dissimilarity in adolescent and maternal representations of type 1 diabetes: Exploration of relations to adolescent well-being. Child Care Health Development 2002;28:369-378.

21. Richards HL, Fortune DG, Chong SLP, Mason DL, Sweeney SKT, Main CJ, Griffiths CEM. Divergent beliefs about psoriasis are associated with increased psychological distress. J Investigative Dermatol 2004;123:49-56.

22. Sterba KR, DeVellis RF, Lewis MA, DeVellis BM, Jordan JM, Baucom DH. Effect of couple illness perception congruence on psychological adjustment in women with rheumatoid arthritis. Health Psychol 2008;27:221-229.

23. Kaptein AA, Scharloo M, Helder DI, Snoei L, van Kempen GMJ, Weinman J, van Houwelingen JC, Roos RAC. Quality of life in couples living with huntington's disease: The role of patients' and partners' illness perceptions. Qual Life Res 2007;16:793-801.

24. Searle A, Norman P, Thompson R, Vedhara K. Illness representations among patients with type 2 diabetes and their partners: Relationships with self-management behaviors. $\mathbf{J}$ Psychosom Res 2007;63:175-184.

25. Benyamini Y, Medalion B, Garfinkel D. Patient and spouse perceptions of the patient's heart disease and their associations with received and provided social support and undermining. Psychol Health 2007;22:765-785. 
26. Cancer Research UK. UK Oesophageal Cancer Statistics. Available from URL: http://info.cancerresearchuk.org/cancerstats/types/oesophagus/index.htm [accessed March 2, 2010].

27. Hodges LJ, Humphris GM. Fear of recurrence and psychological distress in head and neck cancer patients and their carers. Psycho-Oncol 2009;18:841-848.

28. Frick E, Tyroller M, Panzer M. Anxiety, depression and quality of life of cancer patients undergoing radiation therapy: A cross-sectional study in a community hospital outpatient centre. Eur J Cancer Care 2007;16:130-136.

29. Nordin K, Glimelius B. Predicting delayed anxiety and depression in patients with gastrointestinal cancer. Br J Cancer 1999;79:525-529.

30. McCorry NK, Dempster M, Clarke C, Doyle R. Adjusting to life after esophagectomy: the experience of survivors and carers. Qual Health Res 2009;19:1485-1494.

31. Dorrian A, Dempster M, Adair P. Adjustment to inflammatory bowel disease: The relative influence of illness perceptions and coping. Inflamm Bowel Dis 2009;15:47-55.

32. Heijmans M. The role of patients' illness representations in coping and functioning with Addison's Disease. Brit J Health Psychol 1999;4:137-149.

33. Rozema H, Völlnick T, Lechner L. The role of illness representations in coping and health of patients treated for breast cancer. Psycho-Oncol 2009;18:849-857. 
34. Carver CS, Scheier MF, Weintraub JK. Assessing coping strategies: A theoretically based approach. J Personality Soc Psychol 1989;56:267-283.

35. Humphris G, Ozakinci G. The AFTER intervention: A structured psychological approach to reduce fears of recurrence in patients with head and neck cancer. $\mathrm{Br} \mathrm{J}$ Health Psychol 2008;13:223-230. 
Table 1

Descriptive Statistics

\begin{tabular}{|c|c|c|c|c|c|}
\hline & Potential & Survivors' & Carers' & $\mathrm{t}$ & $\mathrm{p}$ \\
\hline & Midpoint & Mean (SD) & Mean (SD) & & \\
\hline HADS Anxiety & 10.5 & $6.42(4.90)$ & $7.77(4.82)$ & 4.488 & $<.001$ \\
\hline HADS Depression & 10.5 & $4.91(4.10)$ & $4.62(3.98)$ & 1.159 & .247 \\
\hline IPQ Acute/chronic timeline & 18 & $23.30(4.68)$ & $23.03(4.80)$ & 0.999 & .318 \\
\hline IPQ Cyclical timeline & 14 & $12.12(3.65)$ & $12.23(3.42)$ & 0.492 & .623 \\
\hline IPQ Treatment control & 15 & $17.17(3.64)$ & $16.77(3.53)$ & 1.746 & .082 \\
\hline IPQ Emotional cause & 15 & $12.12(3.99)$ & $12.52(3.83)$ & 1.732 & .084 \\
\hline IPQ Behavioural cause & 12 & $10.43(3.72)$ & $9.98(3.72)$ & 2.490 & .013 \\
\hline IPQ Externalised cause & 12 & $14.90(3.55)$ & $15.08(3.32)$ & 0.808 & .420 \\
\hline IPQ Consequences & 18 & $21.10(4.82)$ & $\begin{array}{l}22.19 \text { (4.66) } \\
\text { (for survivor) }\end{array}$ & 4.388 & $<.001$ \\
\hline IPQ Consequences & 18 & $21.10(4.82)$ & $\begin{array}{l}12.65(3.20) \\
\text { (for self) }\end{array}$ & 36.222 & $<.001$ \\
\hline IPQ Personal control & 18 & $20.05(4.91)$ & $\begin{array}{l}18.90(4.74) \\
\text { (for survivor) }\end{array}$ & 3.698 & $<.001$ \\
\hline IPQ Personal control & 18 & $20.05(4.91)$ & $\begin{array}{l}16.07 \text { (4.13) } \\
\text { (for self) }\end{array}$ & 12.386 & $<.001$ \\
\hline IPQ Illness coherence & 15 & $19.37(4.28)$ & $\begin{array}{l}19.22(3.85) \\
\text { (for survivor) }\end{array}$ & 0.720 & .472 \\
\hline IPQ Illness coherence & 15 & $19.37(4.28)$ & $\begin{array}{l}19.30(4.04) \\
\text { (for self) }\end{array}$ & 0.239 & .812 \\
\hline CCQ Reflection/relaxation & 12.5 & $9.39(3.23)$ & & & \\
\hline
\end{tabular}




\begin{tabular}{lcc}
\hline CCQ Positive focus & 7.5 & $8.25(2.25)$ \\
CCQ Diversion & 7.5 & $6.41(2.18)$ \\
CCQ Planning & 7.5 & $7.60(2.60)$ \\
CCQ Interpersonal & 17.5 & $14.58(5.59)$ \\
\hline
\end{tabular}


Table 2

Regression Analysis with Survivor Anxiety as the Outcome Variable

$\begin{array}{cc}\text { Unstandardised } & \text { Standardised } \\ \text { regression } & \text { regression } \\ \text { coefficient } & \text { coefficient }\end{array}$

(Constant)

5.268

$1.749 \quad .081$

Patient sex

1.278

.119

$2.908 \quad .004$

Patient age

$-.089$

$-.176$

$-3.982<.001$

No. of months since diagnosis

$-.006$

$-.057$

$-1.399 \quad .163$

Other illnesses for patient

.974

.100

$2.512 \quad .013$

Spousal carer vs other carer

1.487

.067

$1.656 \quad .099$

IPQ Consequences (patient)

.134

.132

$2.519 \quad .012$

IPQ Personal Control (patient)

$-.085$

$-.085$

$-1.997 \quad .047$

IPQ Illness Coherence (patient)

$-.201$

$-.175$

$-4.088<.001$

IPQ Emotional Cause (patient)

$-.075$

$-.073$

$-1.563 \quad .119$

IPQ Acute/chronic Timeline (carer)

.095

.091

$1.498 \quad .135$

IPQ Carer's perception of

$-.128$

$-.091$

$-2.061 \quad .040$

consequences for patient

IPQ Treatment Control (carer)

.265

.217

$4.974<.001$

IPQ Carer's perception of

.236

.154

$2.807 \quad .005$

Consequences for self

IPQ Consequences (patient) X IPQ

.717

.174

$4.259<.001$

Carer's perception of consequences for

patient

CCQ Reflection/relaxation

.251

.166

$3.072 \quad .002$ 
CCQ Positive Focus

CCQ Diversion
$-.345$

.494
$-.160$

.221
$-3.226 \quad .001$

$4.203<.001$ 
Table 3

Regression Analysis with Survivor Depression as the Outcome Variable

$$
\begin{array}{cc}
\text { Unstandardised } & \text { Standardised } \\
\text { regression } & \text { regression } \\
\text { coefficient } & \text { coefficient }
\end{array}
$$$$
\mathrm{t}
$$$$
\mathrm{p}
$$

(Constant)

No. of months since diagnosis

Number of other illnesses for patient

Number of related symptoms

experienced by patient within last

month

IPQ Consequences (patient)

IPQ Personal Control (patient)

IPQ Illness Coherence (patient)

IPQ Emotional Cause (patient)

IPQ Acute/chronic Timeline (carer)

IPQ Carer's perception of

consequences for patient

IPQ Carer's perception of patient's

personal control

IPQ Treatment Control (carer)

IPQ Illness Coherence (carer)

IPQ Behavioural Cause (carer)

IPQ Externalised Cause (carer)

IPQ carer's perception of patient's
10.708

$-.007$

.759

.157

.135

$-.209$

$-.097$

.091

$-.064$

.140

.085

.096

$1.971 \quad .050$

$\begin{array}{lll}-.100 & -2.129 & .034\end{array}$

$\begin{array}{lll}.088 & 1.971 \quad .050\end{array}$

$\begin{array}{lll}-.074 & -1.500 & .135\end{array}$

$\begin{array}{lll}.157 & 2.894 \quad .004\end{array}$

$-.170$

$-.144$

$-2.849 \quad .005$

$-.097$

$\begin{array}{lll}-.093 & -1.644 & .101\end{array}$

.091

.081

$1.878 \quad .061$

$-.109$

$-.088$

$-2.063 \quad .040$

$-.047$

$-.044$

$-.723$

.470 
illness coherence

IPQ Illness Coherence (patient) X IPQ

.249

.087

$2.060 \quad .041$

carer's perception of patient's illness

coherence

CCQ Reflection/relaxation

.290

.226

$4.482<.001$

CCQ Positive Focus

$-.535$

$-.291$

$-5.933<.001$ 
Figure 1. Simple slope analysis for interaction between survivor's perception of consequences and carer's perception of consequences for the survivor

Figure 2. Simple slope analysis for interaction between survivor's perception of illness coherence and carer's perception of survivor's illness coherence 


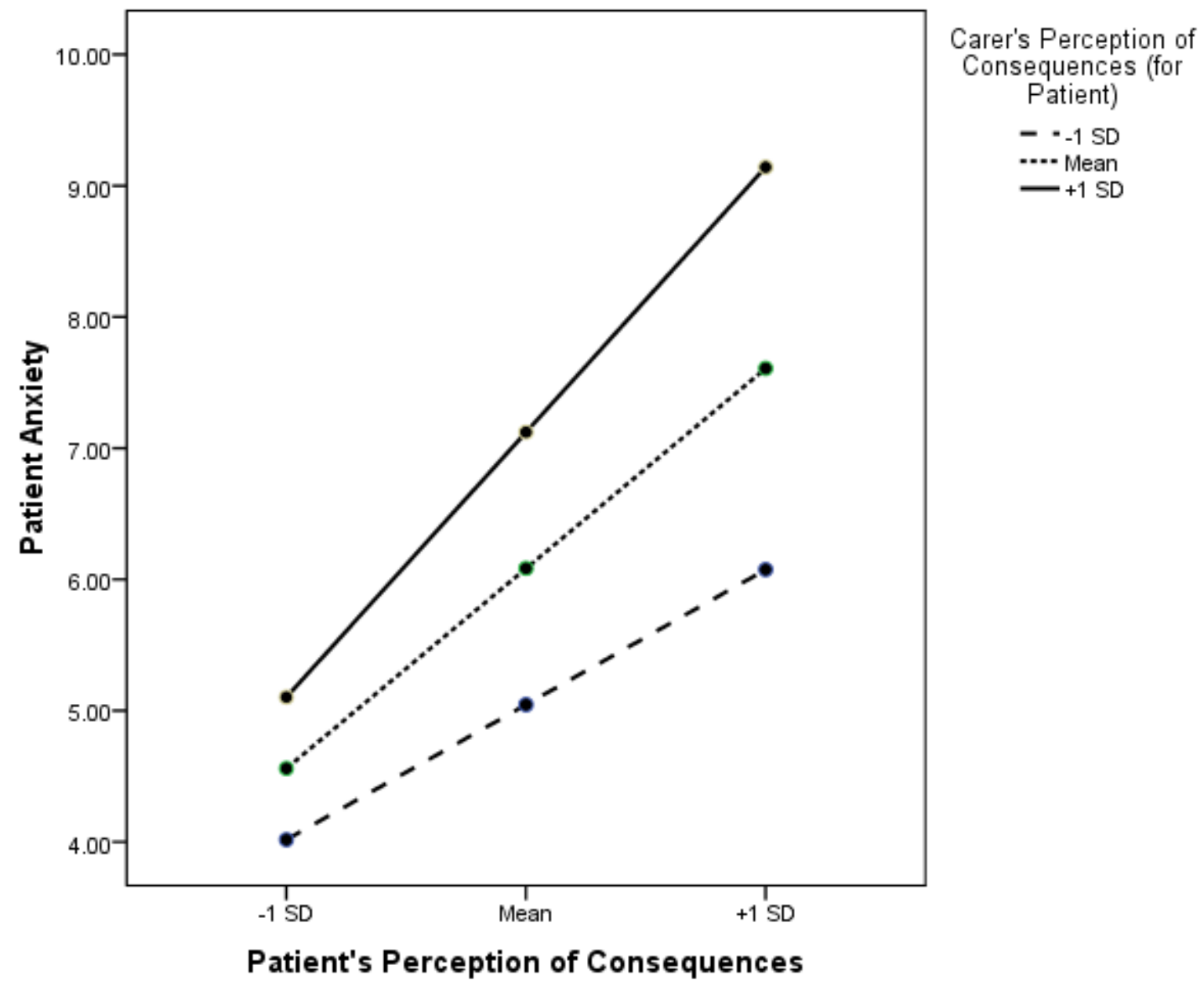




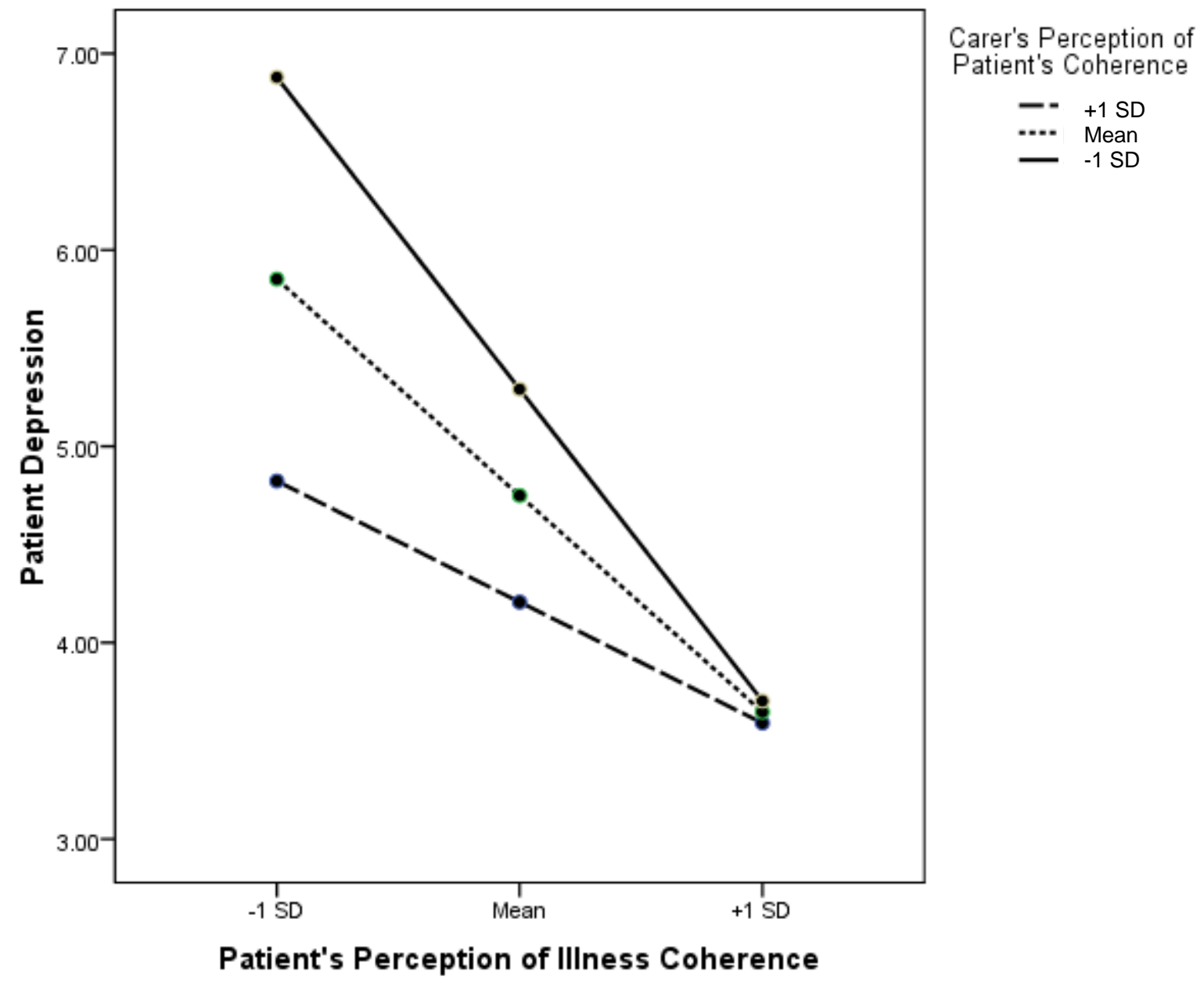

